\title{
Quantifying the contributions of environmental parameters to CERES surface net radiation error in China
}

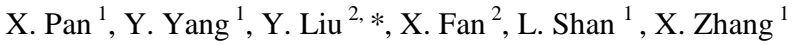 \\ ${ }^{1}$ School of Earth Science and Engineering, Hohai University, Nanjing 211100, China - (px1013, yyb)@ hhu.edu.cn, \\ 15850617829@163.com,15850607350@163.com \\ ${ }^{2}$ Key Laboratory of Watershed Geographic Sciences, Nanjing Institute of Geography and Limnology, Chinese Academy of Sciences, \\ 73 East Beijing Road, Nanjing 210008, China - (ybliu, xwfan)@ niglas.ac.cn
}

\section{Commission VI, WG VI/4}

KEY WORDS: CERES, surface net radiation, China, environmental parameters, error contributions

\begin{abstract}
:
Error source analyses are critical for the satellite-retrieved surface net radiation (Rn) products. In this study, we evaluate the Rn error sources in the Clouds and the Earth's Radiant Energy System (CERES) project at 43 sites from July in 2007 to December in 2007 in China. The results show that cloud fraction (CF), land surface temperature (LST), atmospheric temperature (AT) and algorithm error dominate the Rn error, with error contributions of $\sim-20, \sim 15, \sim 10$ and $\sim 10 \mathrm{~W} / \mathrm{m}^{2}$ (net shortwave (NSW)/longwave (NLW) radiation), respectively. For NSW, the dominant error source is algorithm error (more than $10 \mathrm{~W} / \mathrm{m}^{2}$ ), particularly in spring and summer with abundant cloud. For NLW, due to the high sensitivity of algorithm and large LST/CF error, LST and CF are the largest error sources, especially in northern China. The AT influences the NLW error large in southern China because of the large AT error in there. The total precipitable water has weak influence on Rn error even with the high sensitivity of algorithm. In order to improve Rn quality, CF and LST (AT) error in northern (southern) China should be decreased.
\end{abstract}

\section{INTRODUCTION}

Surface net radiation $(\mathrm{Rn})$ is an important variable for estimating surface energy budgets which drives evaporation, photosynthesis, and surface/atmospheric temperature variations (Denmead,1962; Federer,1968; Idso,1975). Rn is composed by net shortwave radiation (NSW) (the difference between downward $(\mathrm{S} \downarrow)$ and upward $(\mathrm{S} \uparrow)$ shortwave radiation) and net longwave radiation (NLW) (the difference between downward (L $\downarrow$ ) and upward ( $\mathrm{\uparrow} \uparrow$ ) longwave radiation) (Monteith,2008; Jegede,1997; Shi,2013). Remote sensing provides an effective method for obtaining global net radiation data from the CERES (Clouds and the Earth's Radiant Energy System) projects and other projects (Liang,2010; Stackhouse,2011). The retrieval datasets are widely used for investigating regional and global scales because of their temporal continuity and spatial homogeneity (Liang,2005; Gui,2010) .

$\mathrm{Rn}$ product validation has been extensively performed at global scale with high accuracy (with an error below $10 \mathrm{~W} / \mathrm{m}^{2}$ ) (Lin,2008; Kato,2012; Kato,2013). Kato et al. (Kato,2013) compared CRERS monthly $\mathrm{S} \downarrow(\mathrm{L} \downarrow)$ data with ground observations at 24 sites, and reported that it had a bias of -1.70 $\left(-1.00 \mathrm{~W} / \mathrm{m} \mathrm{W} / \mathrm{m}^{2}\right)$ with an root mean square error (RMSE) of $7.80\left(7.60 \mathrm{~W} / \mathrm{m}^{2}\right)$ over the global land area. At regional scale, the radiation components also may have a satisfactory accuracy (Zhang,2015). Zhang et al. (Zhang,2015) validated CERES monthly $\mathrm{S} \downarrow$ data with the aid of GEBA (CMA) ground sites in China. Results show a bias of $5.0\left(8.1 \mathrm{~W} / \mathrm{m}^{2}\right)$ and RMSE of $18.8\left(20.5 \mathrm{~W} / \mathrm{m}^{2}\right)$ in China. However, higher Rn errors (more than $20 \mathrm{~W} / \mathrm{m}^{2}$ ) may be also high in the certain region (Kato,2013; Gui,2009; Gui,2010; Pan,2015). Pan et al. (Pan,2015) showed that $\mathrm{Rn}$ is generally overestimated for
CERES in China, with biases of $26.52 \mathrm{~W} / \mathrm{m} 2$. Previous studies have evaluated the error sources of CERES Rn by using uncertainty analyses or statistically analyses. Kato et al. found the $\mathrm{L} \downarrow$ uncertainty (the largest contribution to Rn uncertainty) was dominated by the near surface temperature and precipitable water (both causing uncertainties of approximately $5 \mathrm{~W} / \mathrm{m}^{2}$ ). The cloud property of CERES was also the important source of uncertainty (Kato,20132; Kato,2013; Kato,2011). In Pan et al.'s research, errors had been attributed to environmental parameters, including surface albedo, surface water vapor pressure, land surface temperature (LST), the normalized difference vegetation index (NDVI) and visibility in a way of statistically analyses (Pan,2015). Though Rn algorithm uncertainty generated by input parameters and the probably affecting factors were identified, the actual error sources remain unclear due to the lack of real input parameter errors.

To address this problem, we analyze linear partial derivatives based on Rn product algorithms and real input errors. Result of this study is helpful to provide recommendations for improving the quality of $\mathrm{Rn}$ products. This paper is organized as follows: Section 2 introduces the methods used for sensitivity and error analyses; Section 3 presents the required data and the data processing methods; Section 4 presents the sources of algorithm sensitivity and the rules of input error propagation, then discusses the main factors that contribute to the Rn errors; Section 5 gives recommendation on which input should be improved for the CERES retrieval of surface net radiation, then discusses the applicability and shortcomings of the analysis method; and Section 6 presents the conclusions.

\footnotetext{
* Corresponding author
} 


\section{METHODS AND DATA}

\subsection{CERES radiation algorithms}

2.1.1 CERES shortwave algorithm: The CERES shortwave data is retrieved through the $\mathrm{Li}$ et al.'s algorithm ( $\mathrm{Li}, 1993)$. It is a simple parameterization that can be used to estimate surfaceabsorbed flux from satellite-measured reflected flux at the top of the atmosphere (TOA). Li et al.'s extensive radiative transfer modeling suggests a linear relationship between the flux reflected by TOA and absorbed at the surface for a fixed solar zenith angle (SZA) for clear skies and under 4 different cloud atmospheric conditions (Eq. 1). The linear relationship is independent of the cloud-optical thickness and surface albedo, strongly depends on the SZA and moderately depends on the precipitable water and cloud type.
$N S W=\frac{E_{0} \cdot\left[\cos \theta-a_{1}-a_{2} \cos ^{x} \theta-\left(1-e^{-\cos \theta}\right)\left(a_{3}+a_{4} W^{y}\right)\right]}{D^{2}}$

$$
-F_{u} \cdot\left(1+a_{5}+a_{6} \ln \cos \theta+a_{7} W^{z}\right)
$$

(1) Where $\theta$ is the SZA; E0 is the TOA insolation; Fu is the TOA upward flux; D is the Earth-Sun distance in astronomical units; and W is the total water vapor amount (TPW). a1 - a7 are the constant coefficients relative to the cloud situation, but CERES products select the situation under clear sky instead of all situations with the coefficient values of $-0.01124,0.1487$, $0.0699,0.0683,0.0542,0.0139$, and 0.0216 , respectively. The coefficients $\mathrm{x}, \mathrm{y}$ and $\mathrm{z}$ are held constant at 0.5 .

2.1.2 CERES longwave algorithm: The CERES longwave product adopts the Gupta et al.'s algorithm (Gupta,1989; Gupta,1992). The algorithm is a parameterization of the radiation transfer equation for surface longwave radiation. Model constants rely on the atmospheric humidity profile from satellite retrieval products. In Gupta et al. algorithm, all-sky L $\downarrow$ radiation is composed of clear sky $L \downarrow$ radiation with a cloud effect correction (Eq. 2 ).

$$
\begin{aligned}
N L W= & \left(A_{0}+A_{1} \ln W+A_{2} \ln ^{2} W+A_{3} \ln ^{3} W\right) T_{e}^{3.7} \\
& +\frac{T_{c b}^{4}}{B_{0}+B_{1} W_{c}+B_{2} W_{c}^{2}+B_{3} W_{c}^{3}} A_{c}-\sigma \varepsilon_{s} T_{s}^{4}
\end{aligned}
$$

(2) where $\sigma$ is the Stefan-Boltzmann constant; Ts is LST; Ac represents the fractional cloud cover $(\mathrm{CF})$; A0 - A3 are the regression coefficients with values of $1.791 \mathrm{E}-07,2.093 \mathrm{E}-08$, 2.748E-09 and 1.184E-09, respectively; Te is the effective emitting temperature of the atmosphere (AT); Tcb represents the cloud base temperature (CBT); Wc represents the water vapor burden below the cloud base (CBV); B0, B1, B2 and B3 are regression coefficients with values of $4.990 \mathrm{E}+07$, $2.688 \mathrm{E}+06,-6.147 \mathrm{E}+03$ and $8.163 \mathrm{E}+02$, respectively; and $\varepsilon \mathrm{s}$ is the land surface emissivity (LSE).

\subsection{Error analysis method}

Radiation product errors mainly result from algorithm and input data errors. In this study, we directly simulated product errors generated by the errors of input parameters. Meanwhile, we also indirectly obtained the algorithm errors by comparing of the difference between simulation and real radiation error (Figure 1). To clarify and quantify the error source, it is necessary to calculate the partial derivative (PDE) for each input parameter of the CERES shortwave and longwave radiation algorithms, and the range values of real input parameters are plugged into the PDEs, and then the algorithm sensitivity of each parameter is simulated at each site (Figure 1). The parametric error analyses were obtained by the product of the PDEs and input parameter errors. The computations of the bias between satellite and ground-observed input variable, e.g. TPW, multiplied PDEs to get the error contributions of each parameter for CERES Rn error. Thus, all error contributions of each environmental parameter can be obtained. In addition, the residuals (the real $\mathrm{Rn}$ errors minus the sum of error contributions) are the combination of NSW and NLW error residuals (real error minus simulated error). For NSW, the discrepancy between simulation and observation is mainly determined by the $\mathrm{Li}$ et al.'s algorithm error. For NLW, the discrepancy is relative to the Gupta et al.'s algorithm error. Besides, the errors of satellite retrieval atmosphere profile and cloud property (determining the water vapor content and temperature below the cloud) are other affecting factors to NLW error residuals. Their error contributions cannot be simulated because of the lack of the atmospheric profile and cloud property reference. Finally, the error contributions of input parameters and algorithm errors were calculated, and then the main sources of data errors were determined. Using these data, error analyses were discussed for 11 sites based on the radiation components (NSW and NLW) and for 43 sites based on $\mathrm{Rn}$. The analyses of error sources were conducted at representative sites at the intra-annual scale to clarify the temporal variations of error sources in the different regions.

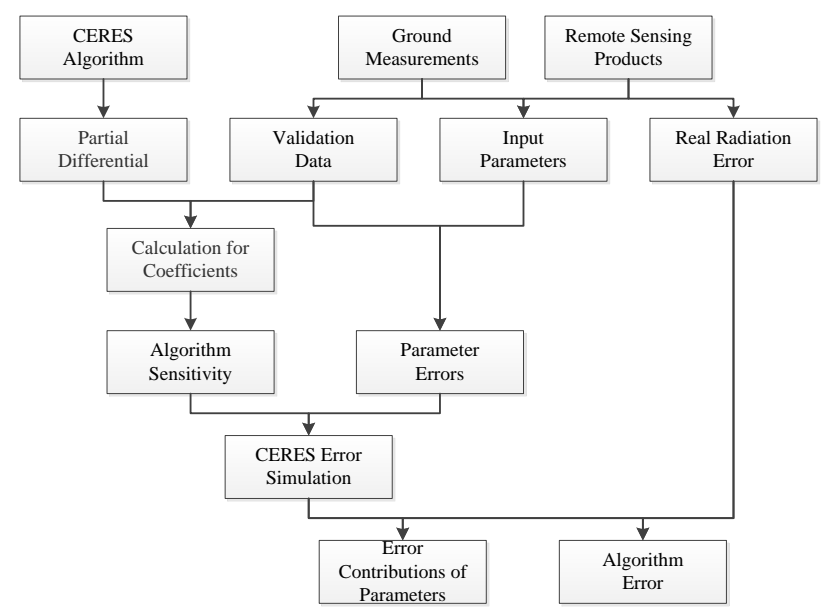

Figure 1. Schematic of the procedure for evaluating the surface radiation error

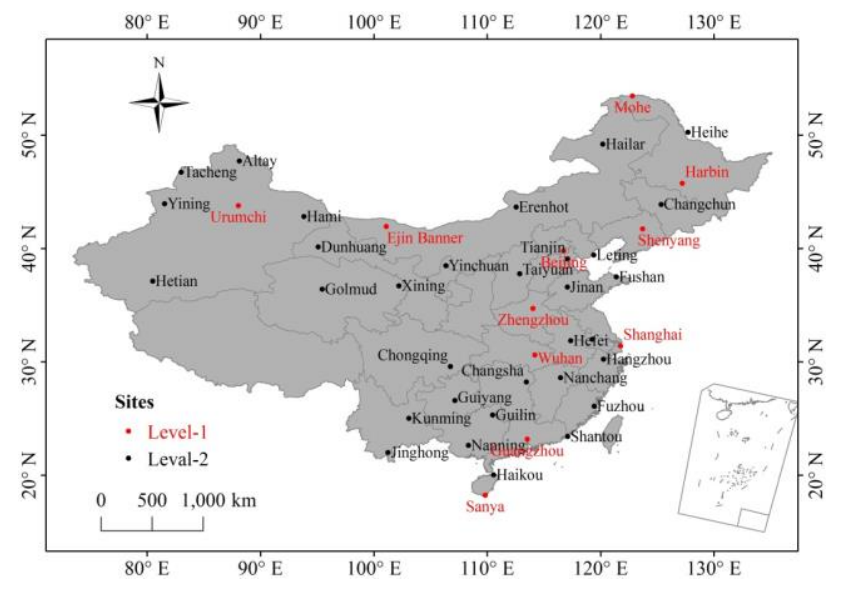

Figure 2. Distribution of surface radiation sites in China 


\subsection{Data}

2.3.1 Ground-measured data: Overall, 43 meteorological (Figure 2) sites are available for error analyses, including 11 level-1 surface radiation observation sites and 32 level-2 sites in China from March in 2000 to December in 2007. The sites are distributed between $18^{\circ} \mathrm{N}$ and $54^{\circ} \mathrm{N}$, and $76^{\circ} \mathrm{E}$ and $128^{\circ} \mathrm{E}$, with altitude ranges from $2.5 \mathrm{~m}$ to $2807.6 \mathrm{~m}$. The sites represent a wide range of landscape, climatic and hydrogeological conditions. These sites measure the surface net radiation, radiation components (only level-1 sites), $0 \mathrm{~cm}$ surface temperature, surface vapor pressure and cloudiness. The data were acquired from the National Meteorological Information/Centre of the Chinese Meteorological Administration (NMIC/CMA, http://cdc.cma.gov.cn). All of the acquired data were quality controlled, and the measurement error of the pyrradiometer was less than $5 \%$, and $3 \%$ for global radiation (Xia,2006;Shi,2008;Tang,2010;Xu,2011).The product parameters were validated for both the satellite retrieval and ground validation data. Ground validation data were derived using surface-based variables. The input parameters of the site observations or parameters that could be determined from the site observations, including TPW, AT, CF and LST, were evaluated when searching for examining $\mathrm{Rn}$ error sources. Furthermore, TPW and AT must be conducted indirectly with other ground observation data. The TPW, W, can be estimated from surface vapor pressure, ew, in China as $W=a_{0}^{\prime}+a_{1}^{\prime} e_{w}+a_{2}^{\prime} e_{w}^{2}$, where a0' - a2' are fitting coefficients depending on the sites (Yang,2002). The AT, Te, is obtained from the surface temperature, Ts, as $T_{e}=55.8+0.77 T_{s}$ ( Bevis, 1992).

2.3.2 Satellite-retrieved data: The CERES datasets are produced, archived, and made available to the scientific community by the Langley Research Center (LaRC), Atmospheric Sciences Data Center (ASDC), the National Aeronautics and Space Administration (NASA) (Wielicki,1996; Smith,2011). The CERES product has a spatial resolution of $1^{\circ} \times 1^{\circ}$ and a temporal resolution of 3 hours, with a mean bias of $29.7 \mathrm{~W} / \mathrm{m} 2$ and a standard deviation of $123.2 \mathrm{~W} / \mathrm{m}^{2}$ (Gui,2010). CERES algorithms use cloud and atmospheric profile information from the Moderate Resolution Imaging Spectroradiometer (MODIS)/ 4-D data assimilation Goddard EOS Data Assimilation System level-4 (GEOS-4) and GEOS-4, respectively. Meanwhile solar insolation and TOA broadband fluxes measured from the Solar Radiation \& Climate Experiment Total Irradiance Monitor and CERES are used for constraints (Atmospheric,2005; CERES,2014). To match the range of ground measured data, monthly $\mathrm{Rn}$ data were obtained from the CERES EBAF-Surface Product (Edition 2.7) from July in 2000 to December in 2007.

The original input data of the radiative flux products are not available for CERES. In this study, we collected the model inputs from the following sources (Table 1 ). The TOA $S \uparrow$ and insolation were obtained from CERES SYN1deg. The cloud properties and SZA were taken from GEOS-4 and SRB SW V3.0, respectively. These datasets are available for NASA, LaRC (Smith,2011; Gupta,1999; Gupta,2006). The Earth-Sun distance in astronomical units was obtained from Solar System Live (http://www.fourmilab.ch/cgi-bin/uncgi/Solar/action?sys=$\mathrm{Si})$.

Several input parameters were calculated by using empirical formulas due to a lack of relevant input data from the remote sensing products. LSE, , is estimated by NDVI obtained from optical hyper-temporal Satellite Pour l'Observation de la Terre (SPOT) VEGETATION (SPOT VGT) data (Van,1993). The dataset is provided by the Cold and Arid Regions Science Data Center at Lanzhou (http://westdc.westgis.ac.cn). In addition, the cloud-base heights are lower than $700 \mathrm{mb}$ at most of the sites in China. Therefore, an atmospheric temperature of less than 700 $\mathrm{mb}$ is used as CBT in the rules of CERES (Wielicki,1997). The cloud parameters from the International Satellite Cloud Climatology Project (ISCCP) DX data products (another accurate cloud product) (Rossow,1993;Rossow,1999; Zhang,2001) were also analyzed to inter-compared with the GEOS-4 cloud data for improving the quality of cloud data.

\begin{tabular}{|c|c|c|c|c|}
\hline $\begin{array}{l}\text { Radiation } \\
\text { Component }\end{array}$ & Parameter & $\begin{array}{c}\text { Base } \\
\text { Variable }\end{array}$ & $\begin{array}{c}\text { Data } \\
\text { Source }\end{array}$ & $\begin{array}{l}\text { Validation } \\
\text { reference }\end{array}$ \\
\hline \multirow{6}{*}{ NSW } & TPW & TPW & GEOS-4 & vapor \\
\hline & SZA & SZA & SRB SW & - \\
\hline & Insolation & Insolation & CERES & - \\
\hline & & & SYN1deg & \\
\hline & TOA & TOA & CERES & - \\
\hline & $\begin{array}{l}\text { upward } \\
\text { flux }\end{array}$ & upward flux & SYN1deg & \\
\hline \multirow{7}{*}{ NLW } & TPW & TPW & GEOS-4 & vapor \\
\hline & $\mathrm{CF}$ & $\mathrm{CF}$ & GEOS-4 & $\mathrm{CF}$ \\
\hline & $\mathrm{CBV}$ & $\begin{array}{c}\text { Humidity } \\
\text { profile }\end{array}$ & GEOS-4 & - \\
\hline & LST & LST & $\begin{array}{l}\text { CERES } \\
\text { SYN1deg }\end{array}$ & $\begin{array}{c}\text { surface } \\
\text { temperatur }\end{array}$ \\
\hline & LSE & NDVI & SPOT & - \\
\hline & AT & $\begin{array}{c}\text { Temperature } \\
\text { profile }\end{array}$ & GEOS-4 & $\begin{array}{c}\text { surface } \\
\text { temperatur } \\
\mathrm{e}\end{array}$ \\
\hline & CBT & $\begin{array}{c}\text { Temperature } \\
\text { profile }\end{array}$ & GEOS-4 & - \\
\hline
\end{tabular}

Table 1. Remote sensing data for estimating radiation errors and the surface observations for validating the parameters

\section{RESULTS AND DISCUSSIONS}

\subsection{Net radiation algorithm sensitivity}

Figure 3 summarized the algorithm sensitivities for each parameter with a unit parameter variation $(1 \mathrm{~K}$ for temperature, 0.01 for emissivity and $\mathrm{CF}$, and $1 \mathrm{~g} / \mathrm{cm}^{2}$ for water vapor amount) In the sensitivity analyses, TPW, CF, CBW, LST, LSE, AT and CBT were derived from the ranges of $0.12 \sim 6.32 \mathrm{~g} / \mathrm{cm}^{2}, 0.17 \sim$ $0.99,0.13 \sim 4.17 \mathrm{~g} / \mathrm{cm}^{2}, 236.23 \sim 312.68 \mathrm{~K}, 0.92 \sim 0.99$, $237.70 \sim 296.57 \mathrm{~K}$ and $249.20 \sim 300.66 \mathrm{~K}$, respectively. In these ranges of parameters, the TPW-induced CERES NSW sensitivity might reach -15 to $-6 \mathrm{~W} / \mathrm{m}^{2}$. For the NLW, the following influencing factors of algorithm sensitivities were obtained (in order of algorithm sensitivity to each parameter): (1) TPW $\left(2 \sim 30 \mathrm{~W} / \mathrm{m}^{2}\right),(2) \mathrm{CF}\left(6 \sim 16 \mathrm{~W} / \mathrm{m}^{2}\right)$, (3) CBW $(0.5 \sim 6.5$ $\left.\mathrm{W} / \mathrm{m}^{2}\right)$, (4) LST (- $\left.6 \sim-3 \mathrm{~W} / \mathrm{m}^{2}\right)$, (5) LSE $\left(-4.5 \sim-2 \mathrm{~W} / \mathrm{m}^{2}\right),(6)$ AT $\left(1 \sim 3.5 \mathrm{~W} / \mathrm{m}^{2}\right)$ and $(7)$ CBT $\left(0.1 \sim 1.8 \mathrm{~W} / \mathrm{m}^{2}\right)$. Evidently, both shortwave and longwave algorithms are highly sensitive to TPW. CF and LST were also the large sensitive parameters to longwave algorithm. In addition, considering that the satellite- 
measured TOA $\mathrm{S} \uparrow$ is an important parameter of NSW algorithm, the calibration of satellite may affect the algorithm uncertainty. Thus, algorithm sensitivity due to TOA $S \uparrow$ should be used to evaluate input uncertainty. This variable resulted in a CERES NSW fluctuation of $2.73 \mathrm{~W} / \mathrm{m}^{2}$ due to an uncertainty of less than $1.5 \%$ in the CERES calibration (Morstad,2011). Generally, the uncertainty of the CERES calibration has a weak influence on the quality of net radiation data.
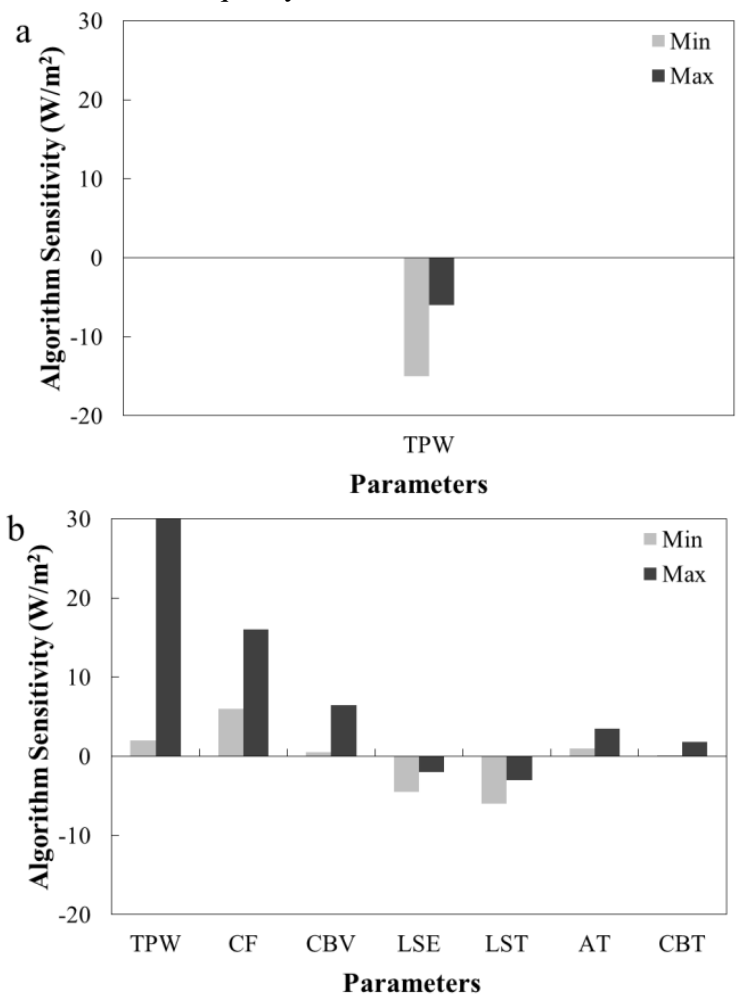

Figure 3. Algorithm sensitivity due to unit variation of input parameters, including the situation of (a) NSW and (b) NLW

\subsection{Error contributions of individual parameters to radiation components}

The Rn error results from the NSW and NLW error. Figure 4 showed Rn error contributions of each parameter, and the NSW and NLW simulated errors accompanying with the real NSW and NLW errors at 11 level-1 sites. The TPW was an unimportant source of NSW error even it might strongly affect the NSW error according to the sensitivity analyses, with an error contribution of $4.13 \mathrm{~W} / \mathrm{m}^{2}$ in Figure 4(a). The discrepancy ranged from $0.92 \mathrm{~W} / \mathrm{m} 2$ (Urumchi) to $19.76 \mathrm{~W} / \mathrm{m}^{2}$ (Sanya) between NSW simulated and real error. That is, the algorithm error was within the range. Thus, there were large shortwave algorithm errors (more than $10 \mathrm{~W} / \mathrm{m}^{2}$ ) at all sites except for Urumchi and Zhengzhou sites.

For NLW, we only evaluated the error sources due to AT (12.94 $\mathrm{W} / \mathrm{m} 2 \mathrm{NLW}$ error), CF (-20.85 W/m $\mathrm{m}^{2} \mathrm{NLW}$ error), LST (16.38 $\mathrm{W} / \mathrm{m} 2$ NLW error) and TPW (-5.74 W/m $\mathrm{m}^{2} \mathrm{NLW}$ error) because the limited types of sites were observed, as shown in Figure 4(b). The LST and CF were the largest error sources, particularly in northern China. In addition, the AT affected the NLW greatly in southern China. The residuals (real error minus the simulated error) ranged from $-15.90 \mathrm{~W} / \mathrm{m} 2$ (Sanya) to 33.49 $\mathrm{W} / \mathrm{m} 2$ (Ejin Banner). The simulations agreed well with the real NLW errors in southern China, as shown in Figure 4(b). The differences of residuals among sites potentially revealed that the combination of Gupta et al.'s algorithm error and the errors of atmosphere profile (cloud property) was less in southern China. The proportionality of the NSW error simulation accounting for Rn was $57.74 \%$, and it was similar to the real proportionality (56\%) (Pan,2015). CF, LST, AT and residuals were the primary error sources, with Rn error contributions of $\sim-20, \sim 15, \sim 10$ and $\sim 10 \mathrm{~W} / \mathrm{m} 2$ (NSW/NLW), respectively. Furthermore, TPW had weak influence on $\mathrm{Rn}$ error.
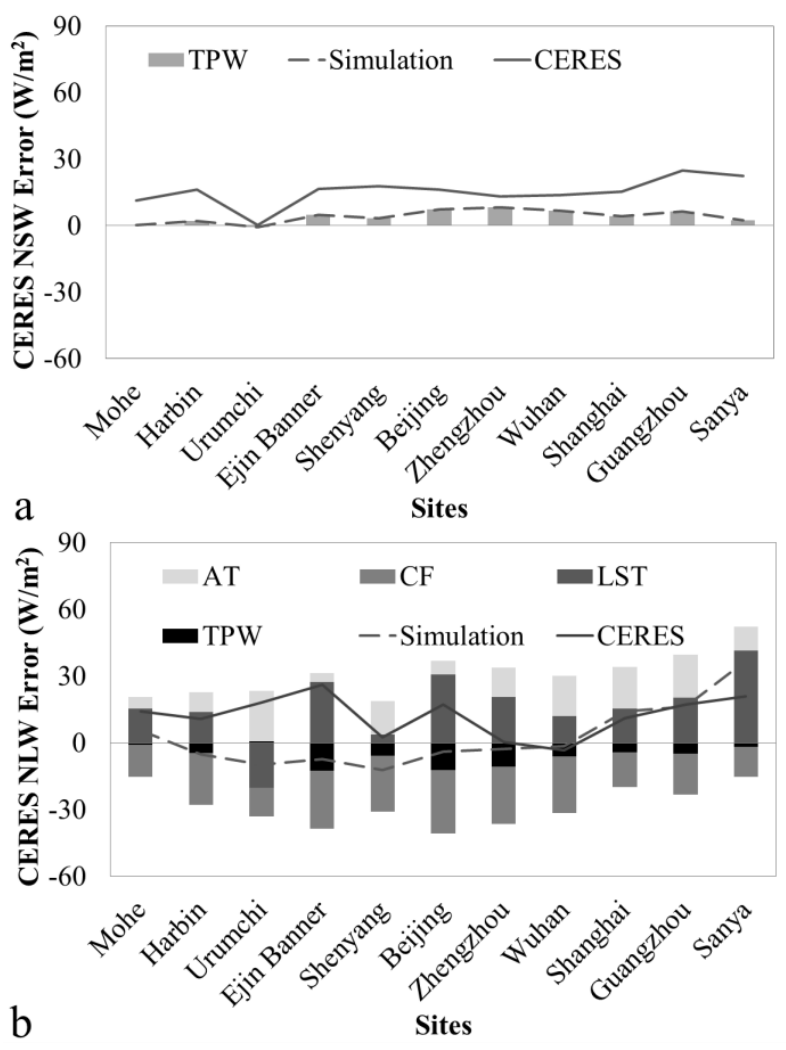

Figure 4. Simulations of the radiation component error sources at the 11 level-1 sites, including the (a) NSW situation, (b)

NLW situation, with the simulated and real error of radiations

\subsection{Error contributions of individual parameters to net radiation}

In order to increase the reliability of analyses about $\mathrm{Rn}$ error contributions, 43 sites with the entire series of input data were selected, and the Rn error contributions of each input parameter were calculated in Figure 6. The residuals consisted of the NSW and NLW error residuals (real error minus simulative error) were also shown in Figure 6. The monthly mean CERES Rn were $79.62 \mathrm{~W} / \mathrm{m}^{2}$, with errors of $27.24 \mathrm{~W} / \mathrm{m}^{2}$ compared to 50 surface site measurements in China (Pan,2015). The average simulated Rn errors were $7.43 \mathrm{~W} / \mathrm{m}^{2}$ at 43 sites in China.

Figure 5 showed that the CERES Rn error contributions of LST were large in the northern regions, which was mainly attribute to the considerable LST error and high LST sensitivity. The LST contributions to Rn error ranged from $-20.22 \mathrm{~W} / \mathrm{m}^{2}$ to $53.91 \mathrm{~W} / \mathrm{m}^{2}$, with an average value of $18.88 \mathrm{~W} / \mathrm{m}^{2}$. The low error contribution of LST (less than $15 \mathrm{~W} / \mathrm{m}^{2}$ ) only appeared at some sites in southern China. Other than these sites, the AT and $\mathrm{CF}$ were the main error sources in China and had resulted in $\mathrm{Rn}$ errors of $13.09 \mathrm{~W} / \mathrm{m}^{2}$ and $-18.51 \mathrm{~W} / \mathrm{m}^{2}$, respectively. The AT mainly affected $\mathrm{Rn}$ error in southern China and caused 16.92 $\mathrm{W} / \mathrm{m}^{2}$ of $\mathrm{Rn}$ error. The CF contributions ranged from - 29.01 
$\mathrm{W} / \mathrm{m}^{2}$ to $-1.82 \mathrm{~W} / \mathrm{m}^{2}$, and large error contributions (approximately $-20 \mathrm{~W} / \mathrm{m}^{2}$ ) were observed at most of sites. The TPW contributed - $12.91 \mathrm{~W} / \mathrm{m} 2$ to $\mathrm{Rn}$ error in northwestern China. The sites with large residuals (approaching to $20 \mathrm{~W} / \mathrm{m}^{2}$ ) were concentrated in northern China.

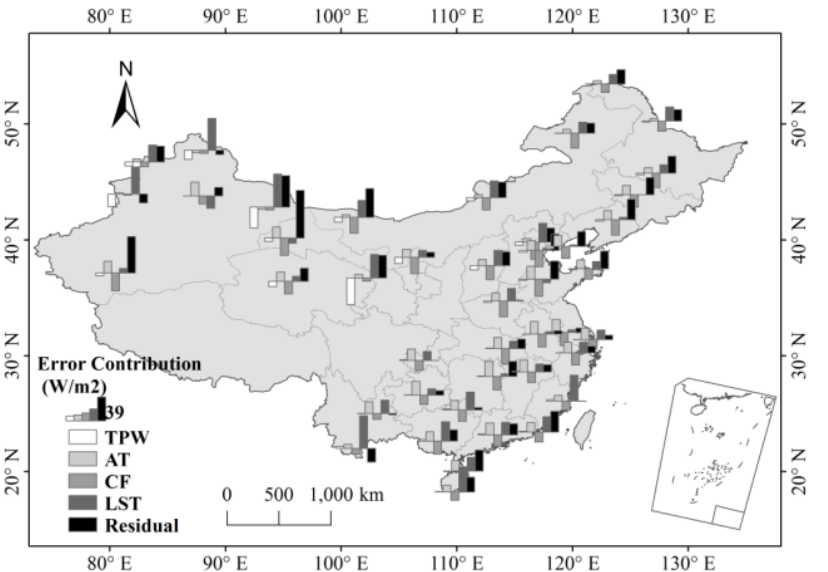

Figure 6. Main sources of net radiation error for CERES

\subsection{Implications for improving product accuracy}

Regarding the direct sources of Rn error, it is necessary for improving the NSW quality firstly. The input error must be taken into consideration for sensitive parameters. Overall, CF, LST and AT were the main influencing factors of Rn error. Figure 6 and Figure 7 show the disagreements between satellite observations and site observations. The averages are $285.11 \mathrm{~K}$ and $289.38 \mathrm{~K}$ for the satellite-derived and observed LST throughout China. The difference between the datasets ranges from $-14.7 \mathrm{~K}$ to $3.5 \mathrm{~K}$. The greatest differences (more than $7 \mathrm{~K}$ ) of 9 sites are mainly located in northern China. The satellitederived and observed AT averages are $282.90 \mathrm{~K}$ and $278.58 \mathrm{~K}$ over the sites, with the differences ranging from $-4.2 \mathrm{~K}$ to $8.1 \mathrm{~K}$. Many sites with differences of about $6 \mathrm{~K}$ are located in southern China. That indicates LST dominates the NLW error in northern China, while AT dominates the NLE error in southern China.

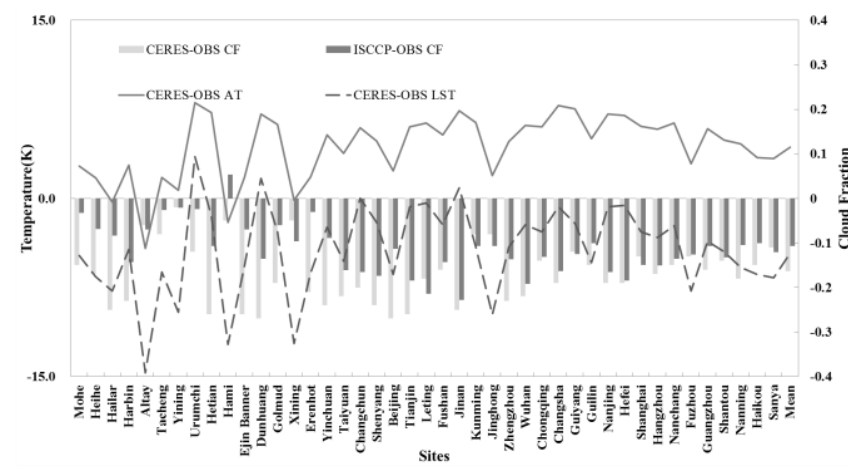

Figure 6. Multi-year average difference in the LST, AT and CF between the satellite and site measurements (OBS) at 43 sites

CERES cloud data were obtained from GEOS-4 (Bloom,2005). The CERES, ISCCP and site-observed CF values are $0.56,0.62$ and 0.72 throughout China. The difference between the CERES and ground-observed CF ranges from -0.32 to 0.09 . The 17 sites with largest difference (more than 0.2) are mainly located in northern China, which suggests the larger CF error accompanying with the larger NLW error contributions. In addition, the differences between ISCCP and ground-observed $\mathrm{CF}$ are below 0.2 at most of the sites. The CERES CF is similar to the ISCCP CF in southern China. It seems that the ISCCP CF is more accurate than $\mathrm{CF}$ derived from GEOS-4. Therefore, ISCCP CF can be a satisfactory CF input, rather than GEOS-4 $\mathrm{CF}$, for the CERES NSW algorithm. Besides the quality of CERES CF data, the amount of CF is also related to the accuracy of simulation. The CERES NSW product adopts the coefficients of $\mathrm{Li}$ et al.'s algorithm for clear skies to represent those of all skies (Li,1997; Wielicki,1998), the amount of CF among sites may affect the accuracy of shortwave algorithm. The CF is usually larger in autumn and winter in southern China, which would generate a greater error for the NSW algorithm.
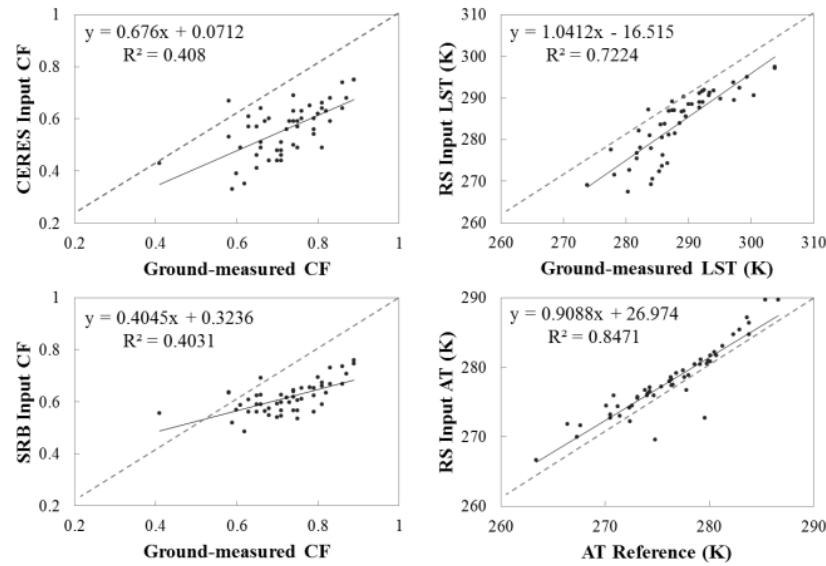

Figure 7. Multi-year mean of LST, AT and CF derived by satellite and site observations at 43 sites

Quality of the CERES Rn data can be improved by error improvements of the input data and the retrieval algorithm. With respect to the dominating sources of the Rn error, it indicates that the input should be improved for the CERES retrieval of Rn. Specifically, CF and LST should be improved when considering the results of the sensitivity analyses above. Although AT is insensitive for the algorithm, it needs improvement because of its large AT input error, especially in southern China. Specially, the CF and LST errors should be decreased in northern China, and the AT error should be decreased in southern China. ISCCP DX product is another satisfactory cloud product that can be used in the retrieval procedure. It is not necessary to improve TPW because of its weak error contribution for the Rn error. For CERES NSW data production, the coefficients of $\mathrm{Li}$ et al.'s algorithm should be reselected under all sky instead of clear sky according to the cloud property, especially in situation of abundant cloud. The qualities of atmosphere profile and cloud property (Gupta et al.'s algorithm) need to be improved for NLW in northern China.

\section{CONCLUSIONS}

This study evaluates CERES radiation dataset errors under all sky conditions from July in 2000 to December in 2007 in China. The retrieval input parameters and the surface-observed net radiation data at 43 CMA ground radiation sites (11 level-1 sites and 32 level-2 sites) in China are used for analysis. The study quantifies the contributions of environmental parameters to CERES Rn product error and reveals the retrieval algorithm errors. It also provides some guides for the improvement of the Rn product. 
CERES net radiation algorithms are highly sensitive to TPW, CF and LST. In the view of 11 level-1 sites, CF, LST, AT and residuals are main $\mathrm{Rn}$ error sources, with error contributions of $\sim-20 \mathrm{~W} / \mathrm{m}^{2}, \sim 15 \mathrm{~W} / \mathrm{m}^{2}, \sim 10 \mathrm{~W} / \mathrm{m}^{2}$ and $\sim 10 \mathrm{~W} / \mathrm{m}^{2}$ (NSW/NLW), respectively. Furthermore, TPW has weak influence on Rn error The contributions of TPW, AT, CF and LST are $-4.17 \mathrm{~W} / \mathrm{m}^{2}$, 13.09 W/m ${ }^{2},-18.51 \mathrm{~W} / \mathrm{m}^{2}$, and $18.88 \mathrm{~W} / \mathrm{m}^{2}$ for the 43 sites. In details, the TPW error has weak contribution to the NSW error, while the Li et al.'s algorithm errors (inducing NSW error of general more than $10 \mathrm{~W} / \mathrm{m}^{2}$ ) dominate the error. The LST and $\mathrm{CF}$ are the largest NLW error sources, especially in northern China. The AT influences the NLW greatly in southern China. The Gupta et al.'s algorithm error or the error contribution of atmosphere profile (cloud property) is less in southern China. Based on the analyses of error contributions, in order to improve the quality of CERES Rn data, the CF (AT) error in northern (southern) China should be decreased, and the LST error in western China should be decreased. In additional, the Li et al.'s algorithm should be reselected under all sky in the data production, especially in situation of abundant cloud. The qualities of atmosphere profile and cloud property (Gupta et al.'s algorithm) also need to be improved for NLW in northern China.

\section{ACKNOWLEDGEMENTS}

This work is supported by the National Nature Science Foundation of China (41430855; 41701487), the China Postdoctoral Science Foundation Funded Project (2017M611665), the Jiangsu province Postdoctoral Science Foundation Funded Project (1701056C), the Fundamental Research Funds for the Central Universities of China (2017B16514) and the Jiangsu Provincial Research Projects of Surveying Mapping and Geoinfomation (JSCHKY201706).

\section{REFERENCES}

Atmospheric Science Data Center; CERES Terra Edition2A SSF Cloud Properties - Accuracy and Validation,https://eosweb.larc.nasa.gov/sites/default/files/projec t/ceres/quality_summaries/ssf_cloud_prop_terra_ed2A.pdf, 2005.

Bevis, M.; Businger, S.; Herring, T. A.; Rocken, C.; Anthes, R. A.; Ware, R. H.; GPS meteorology: Remote sensing of atmospheric water vapor using the Global Positioning System. Journal of Geophysical Research: Atmospheres (1984-2012). 1992, 97(D14), 15787-15801.

Bloom, S.; Da Silva, A.; Dee, D.; Bosilovich, M.; Chern, J. D.; Pawson, S.; Wu, M. L.; Documentation and validation of the Goddard Earth Observing System (GEOS) data assimilation system-Version 4. NASA Tech. Memo. 2005, 104606: 187.

CERES; CERES_EBAF-Surface_Ed2.8 Data Quality Summary.http://ceres.larc.nasa.gov/documents/DQ_summaries/ CERES_EBAF-Surface_Ed2.8_DQS.pdf, 2014.

Denmead, O. T.; Fritschen, L. J.; Shaw, R. H.; Spatial distribution of net radiation in a corn field. Agronomy Journal. 1962, 54(6), 505-510.

Fan, X.; Liu, Y.; Tao, J.; Weng, Y.; Soil Salinity Retrieval from Advanced Multi-Spectral Sensor with Partial Least Square Regression. Remote Sensing. 2015, 7(1), 488-511.
Federer, C. A.; Spatial variation of net radiation, albedo and surface temperature of forests. Journal of Applied Meteorology. 1968, 7(5), 789-795.

Gupta, S. K.; A parameterization for longwave surface radiation from sun-synchronous satellite data. Journal of Climate. 1989, 2(4), 305-320.

Gupta, S. K.; Darnell, W. L.; Wilber, A. C.; A parameterization for longwave surface radiation from satellite data: Recent improvements. Journal of Applied Meteorology. 1992, 31(12), 1361-1367.

Gupta, S. K.; Ritchey, N. A.; Wilber, A. C.; Whitlock, C. H.; Gibson, G. G.; Stackhouse Jr, P. W.; A climatology of surface radiation budget derived from satellite data. Journal of Climate. 1999, 12(8), 2691-2710.

Gupta, S. K.; Stackhouse Jr, P. W.; Cox, S. J.; Mikovitz, J. C.; Zhang, T.; Surface radiation budget project completes 22-year data set. GEWEX News. 2006, 16(4), 12-13.

Gui, S.; Liang, S.; Li, L.; Validation of surface radiation data provided by the CERES over the Tibetan Plateau. Geoinformatics, 2009 17th International Conference on. IEEE, 2009, 1-6.

Gui, S.; Liang, S.; Wang, K.; Li, L.; Zhang, X.; Assessment of three satellite-estimated land surface downwelling shortwave irradiance data sets. Geoscience and Remote Sensing Letters, IEEE. 2010, 7(4), 776-780.

Gui, S.; Satellite remote sensing of surface net radiation. PH.D dissertation. Wuhan University, Wuhan, Hubei, China, 2010. (in Chinese).

Hakuba, M. Z.; Folini, D.; Sanchez - Lorenzo, A.; Wild, M.; Spatial representativeness of ground - based solar radiation measurements. Journal of Geophysical Research: Atmospheres. 2013, 118(15), 8585-8597.

Idso, S. B.; Aase, J. K.; Jackson, R. D.; Net radiation—soil heat flux relations as influenced by soil water content variations. Boundary-Layer Meteorology. 1975, 9(1), 113-122.

Jegede, O. O.; Daily averages of net radiation measured at Osu, Nigeria in 1995. International journal of climatology; 1997, 17(12), 1357-1367.

Kato, S.; Loeb, N. G.; Rose, F. G.; Doelling, D. R.; Rutan, D. A.; Caldwell, T. E.; Yu, L.; Weller, R. A.; Surface irradiances consistent with CERES-derived top-of-atmosphere shortwave and longwave irradiances. Journal of Climate. 2013, 26(9), 2719-2740.

Kato, S.; Loeb, N. G.; Rutan, D. A.; Rose, F. G.; Sun-Mack, S.; Miller, W. F.; Chen, Y.; Uncertainty estimate of surface irradiances computed with MODIS-, CALIPSO-, and CloudSatderived cloud and aerosol properties. Surveys in Geophysics. 2012, 33(3-4), 395-412.

Kato, S.; Rose, F. G.; Sun - Mack, S.; Miller, W. F.; Chen, Y.; Rutan, D. A.; Stephens, G.L.; Loeb, N. G.; Minnis, P.; Wielicki, B. A.; Winker, D. W.; Charlock, T. P.; Stackhouse Jr, P. W.; $\mathrm{Xu}$, K. M.; Collins, W. D.; Improvements of top - of atmosphere and surface irradiance computations with CALIPSO 
- , CloudSat - , and MODIS - derived cloud and aerosol properties. Journal of Geophysical Research: Atmospheres (1984 - 2012). 2011, 116(D19).

Liang, S.; Quantitative Remote Sensing of Land Surfaces (Vol. 30). John Wiley \& Sons, 2005.

Liang, S.; Wang, K.; Zhang, X.; Wild, M; Review on estimation of land surface radiation and energy budgets from ground measurement, remote sensing and model simulations. Selected Topics in Applied Earth Observations and Remote Sensing, IEEE Journal of. 2010, 3(3), 225-240.

Lin, B.; Stackhouse Jr, P. W.; Minnis, P.; Wielicki, B. A.; Hu, Y.; Sun, W.; Fan, T.; Hinkelman, L. M.; Assessment of global annual atmospheric energy balance from satellite observations. Journal of Geophysical Research: Atmospheres (1984-2012). 2008, 113(D16).

Li. Z., Kratz. D.P.; Clouds and the Earth's Radiant Energy System (CERES) Algorithm Theoretical Basis Document: Estimate of Shortwave Surface Radiation Budget From CERES (Subsystem http://ceres.larc.nasa.gov/documents/ATBD/pdf/r2_2/ceresatbd2.2-s4.6.1.pdf, 1997.

Li, Z.; Leighton, H. G.; Masuda, K.; Takashima, T.; Estimation of SW flux absorbed at the surface from TOA reflected flux. Journal of Climate. 1993, 6(2), 317-330.

Monteith, J.; Unsworth, M.; Principles of Environmental Physics. Academic Press, 2008.

Morstad, D. L.; Doelling, D. R.; Bhatt, R.; Scarino, B.; The CERES calibration strategy of the geostationary visible channels for CERES cloud and flux products. International Society for Optics and Photonics. In SPIE Optical Engineering+ Applications. 2011, 815316-815316.

Pan, X.; Liu, Y.; Fan, X.; Comparative assessment of satelliteretrieved surface net radiation: An examination on CERES and SRB datasets in China. Remote Sensing. 2015, 7, 4899-4918.

Rossow, W. B.; Garder, L. C.; Validation of ISCCP cloud detections. Journal of Climate. 1993, 6(12), 2370-2393.

Rossow, W. B.; Schiffer, R. A.; Advances in understanding clouds from ISCCP. Bulletin of the American Meteorological Society. 1999, 80(11), 2261-2287.

Shi, G. Y.; Hayasaka, T.; Ohmura, A.; Chen, Z. H.; Wang, B.; Zhao, J. Q.; Che, H. Z.; Xu, L.; Data quality assessment and the long-term trend of ground solar radiation in China. Journal of Applied Meteorology and Climatology. 2008, 47(4), 1006-1016.

Shi, Q.; Liang, S.; Characterizing the surface radiation budget over the Tibetan Plateau with ground - measured, reanalysis, and remote sensing data sets: 1. Methodology. Journal of Geophysical Research: Atmospheres. 2013, 118(17), 9642-9657.

Smith, G. L.; Priestley, K. J.; Loeb, N. G.; Wielicki, B. A.; Charlock, T. P.; Minnis, P.; Doellinga, D. R.; Rutan, D. A.; Clouds and Earth Radiant Energy System (CERES), a review: Past, present and future. Advances in Space Research. 2011, 48(2), 254-263.
Stackhouse Jr, P. W.; Gupta, S. K.; Cox, S. J.; Zhang, T.; Mikovitz, J. C.; Hinkelman, L. M.; 24.5-year SRB data set released. GEWEX News. 2011, 21(1), 10-12.

Tang, W.; Yang, K.; He, J.; Qin, J.; Quality control and estimation of global solar radiation in China. Solar Energy. 2010, 84(3), 466-475.

Van de Griend, A. A.; Owe, M.; On the relationship between thermal emissivity and the normalized difference vegetation index for natural surfaces. International Journal of Remote Sensing. 1993, 14(6), 1119-1131.

Wielicki, B. A.; Barkstrom, B. R.; Harrison, E. F.; Lee III, R. B.; Louis Smith, G.; Cooper, J. E.; Clouds and the Earth's Radiant Energy System (CERES): An earth observing system experiment. Bulletin of the American Meteorological Society. 1996, 77(5), 853-868.

Wielicki, B. A.; Baum, B. A.; Coakley, J. A.; Green, R. N.; Hu, Y.; King, M. D.; Lin, B.; Kratz, D. P.; Minnis, P.; Stowe, L. L.; Clouds and the Earth's Radiant Energy System (CERES) Algorithm Theoretical Basis Document: Overview of Cloud Retrieval and Radiative Flux Inversion (Subsystem 4.0), http://ceres.larc.nasa.gov/documents/ATBD/pdf/r2_2/ceresatbd2.2-s4.0.pdf, 1997.

Wielicki, B.; Barkstrom, B. R.; Baum, B.; Charlock, T. P.; Green, R. N.; Kratz, D. P.; Lee III, R. B.; Minnis, P.; Smith, L. G.; Wong, T.; Young, D. F.; Cess, R. D.; Coakley, J. A.; Crommelynck, D. A. H.; Donner, L.; Kandel, R.; King, M. D.; Miler, A. J.; Ramanathan, V.; Randall, D. A.; Stowe, L. L.; Welch, R. M.; Clouds and the Earth's Radiant Energy System (CERES): algorithm overview. Geoscience and Remote Sensing, IEEE Transactions on. 1998, 36(4), 1127-1141.

Xia, X. A.; Wang, P. C.; Chen, H. B.; Liang, F.; Analysis of downwelling surface solar radiation in China from National Centers for Environmental Prediction reanalysis, satellite estimates, and surface observations. Journal of Geophysical Research: Atmospheres (1984-2012). 2006, 111(D9).

Xu, J.; Masuda, K.; Ishigooka, Y.; Kuwagata, T.; Haginoya, S.; Hayasaka, T.; Yasunari, T.; Estimation and verification of daily surface shortwave flux over China. Journal of the Meteorological Society of Japan. 2011, 89, 225-238.

Yang, J.; Qiu, J.; A Method for Estimating Precipitable Water and Effective Water Vapor Content from Ground Humidity Parameters. Chinese Journal of Atmospheric Sciences. 2002, 1, 001 .

Zhang, X.; Liang, S.; Wild, M.; Jiang, B.; Analysis of surface incident shortwave radiation from four satellite products. Remote Sensing of Environment. 2015, 165, 186-202.

Zhang, Y.; Rockel, B.; Stuhlmann, R.; Hollmann, R.; Karstens, U.; REMO cloud modeling: Improvements and validation with ISCCP DX data. Journal of Applied Meteorology. 2001, 40(3), 389-408. 